\title{
Argumentation of Prospective Mathematics Teachers in Fraction Tasks Mediated by an Online Assessment System With Automatic Feedback
}

\author{
Jorge Gaona ${ }^{1 \star}$, Romina Menares ${ }^{2}$ \\ ${ }^{1}$ Centro de Estudios Avanzados, Universidad de Playa Ancha, CHILE \\ ${ }^{2}$ Instituto de Matemáticas, Universidad de Valparaíso, CHILE
}

Received 29 August 2021 - Accepted 5 December 2021

\begin{abstract}
This article reports the argumentation work of a group of trainee mathematics teachers in an experiment carried out in a virtual class (due to the emergence of COVID-19) during 2020. They worked with a task on fractions in an online assessment system with questions with random parameters and infinite possible correct answers. This was followed by a discussion of the strategies and the justifications, arguments and validations of these strategies and other conjectures that emerged. This article analyzes this work from a qualitative approach using the Mathematical Working Space as a theoretical framework. The results show that the discussion work led the trainee teachers to find interpretations for the algorithms processed by the computer, enhancing epistemic discourse and argumentation in the context of the use of technological artifacts. In turn, the same discourses allowed the future teachers to instrumentalize the processes to be used in new tasks.
\end{abstract}

Keywords: mathematics education, digital technology, proof and discourse, task design, online teaching/learning strategies

\section{INTRODUCTION}

According to Balacheff (1987), we must differentiate between an explanation or argumentation, a proof, and a demonstration. The first -an argumentation- is a discourse that seeks to make something understandable or convince about the veracity of a proposition; a proof is an explanation accepted by a community; and a demonstration is a type of proof with a specific structure that is characterized by being a chain of statements organized according to specific rules. More specifically, Duval (1993), in addition to making this distinction, points out that the strength of an argument depends on its epistemic value and on not containing contradictions with other arguments. Also, the literature shows that considering the processes of argumentation and proof together can help to improve the understanding of the mathematical objects involved and the process of proof and demonstration. However, the literature is more abundant in diagnoses of the difficulties (especially in geometry) than proposals to address them (Stylianides et al., 2016). In mathematics education, it is proposed to value those proofs that can help to explain and justify conjectures based on mathematical elements (Hanna, 2001).

In Chile, the secondary school curriculum bases explicitly propose argumentation as one of the skills to be developed in mathematics (MINEDUC, 2019). The research community in mathematics education in the country has been reporting different results on argumentation in teacher training. In initial secondary school teacher training, different studies have been carried out. In geometry, Nagel et al. (2008) state that many first-year students are able to order their arguments deductively, however, they still do not have the ability to develop deductive arguments in all the proposed tasks, even though they attend a university that receives students of a high academic level. In another research on initial training on systems of linear equations, Rodríguez-Jara et al. (2019) observe that students argue erroneously on the basis of the proportionality of the coefficients, and according to the authors, this shows that they have not coordinated some processes related to the mathematical objects involved.

(c) 2021 by the authors; licensee Modestum. This article is an open access article distributed under the terms and conditions of the Creative Commons Attribution License (http://creativecommons.org/licenses/by/4.0/). 


\section{Contribution to the literature}

- This article contributes as a proposal to promote argumentation through open tasks mediated with technology.

- This article shows the transit of students from instrumental argumentation processes to discursive argumentation processes from a task in a digital environment and discussion with the teacher and the whole class.

- Also, from a theoretical point of view, this article shows how students instrumentalize a discursive argumentation process.

There is another interesting group of results on argumentation, in this case, from practicing teachers. In primary education, Pizarro et al. (2018) conclude that weaknesses in estimation knowledge do not allow teachers to argue adequately. In another paper on integer numbers, Solar (2018) shows the importance of some strategies for the professor to encourage argumentation: giving opportunities for participation, managing error and asking specific types of questions, such as questions that favor explanation, avoiding rhetorical questions, asking counter questions and questions that keep the focus on the discussion.

As for secondary education, several research studies report on the argumentations in mathematics work proposed by novice teachers in their classes. For example, Henríquez-Rivas and Montoya-Delgadillo (2015), and Montoya-Delgadillo et al. (2014) point out that, in the classes of beginning teachers of algebra and geometry, the work of argumentation is relegated or almost absent. Furthermore, along the same lines and considering argumentation as part of discursive work within a more general mathematical work, which considers semiotic and instrumental aspects (Kuzniak et al. (2016), Henríquez-Rivas and Montoya-Delgadillo (2016) show that there are tasks that encourage discursive work, although difficulties are still observed in developing this dimension when they are implemented. In the area of probability, MontoyaDelgadillo et al. (2016) report that new teachers find that they have not had the necessary experience to promote argumentative processes. These authors conclude that for teachers, demonstration processes are not viable at the school level at which they are working, which leads them to favor the operative. Moreover, as they are still very close to their training institution, their performance in the classroom is in tension between what they think as mathematicians and what they think as teachers.

At the international level, when searching on the Scopus and Web of Science literature database on teacher argumentation, we found that argumentation in teacher education has also been addressed in different places. In the United States and in the United Kingdom, primary school teachers were studied in arithmetic work (Stylianides \& Stylianides, 2009). These authors concluded that teachers have a good understanding of the distinction between proof and empirical arguments, although teachers face a number of challenges when solving a task that involves argumentation, such as differentiating between describing and explaining, or coordinating interpretations with strategies, among others (Lo et al., 2008, Stylianides \& Stylianides, 2009). When in the role of teachers, the greatest difficulties are related to implementing high-level tasks related to reasoning and demonstration and managing students' pre-existing habits of mind that were not attuned to mathematical sense-making (Stylianides et al., 2013).

Belin and Akar (2020) addressed argumentation with real numbers and showed that after instruction where different representations were worked on, prospective teachers generated their own examples and drew diagrams while explaining the statements and notations given in the argumentations, where decimals were used to work with periodic numbers. This type of instruction can overcome epistemological obstacles, as per Bachelard (1938) on the comparison between numbers using different periodic notations (Mena-Lorca et al., 2014).

When in the literature search we add words related to technology to enhance argumentation in future teachers, the research is rather scarce; there are articles that use mathematics software to assist argumentation and there are others where technology is the means of communication to support the students' argumentation work. In the first case, the papers by Stupel and BenChaim (2017), and Zengin (2017) are available, who used GeoGebra to support argumentation and proof work in geometry tasks. In Stupel and Ben-Chaim (2017), several different theorems are presented whose proof is done initially using the dynamic geometry software and later classically. In Zengin (2017), students were shown multiple solutions to a task, some of which were initially explored using GeoGebra. In both investigations, students had a good attitude towards the argumentation then towards the work proposed by the researchers.

On the other hand, journal articles in which technology is the means of communication are scarce. The search found only the work by Fernández et al. (2012). This paper underlines that the format certainly presents additional challenges to the argumentation process. The research shows an arithmetic task, and reflects on how an online discussion can be conducted 


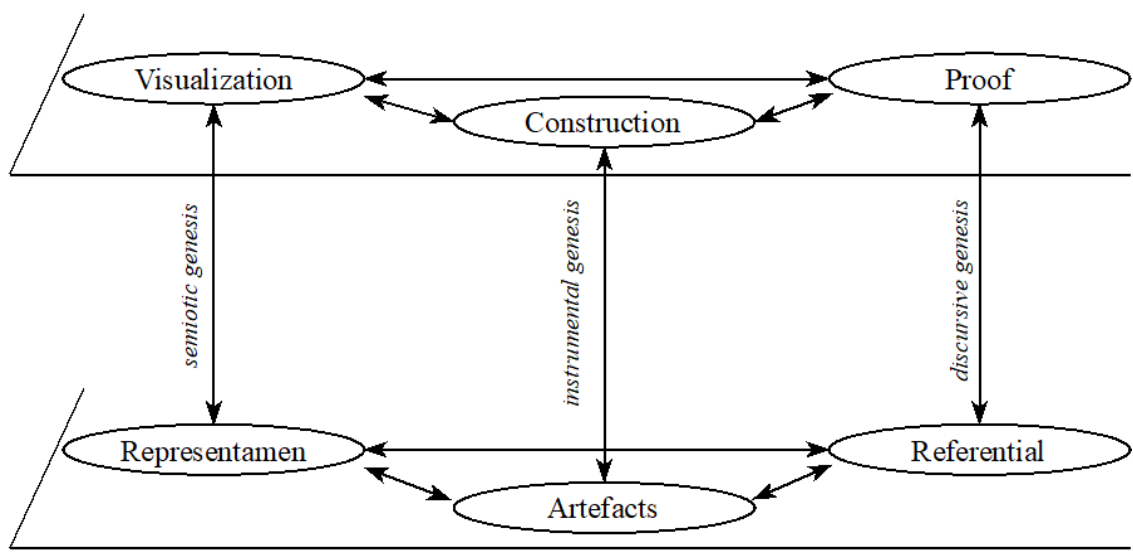

Figure 1. Mathematical Working Space. Taken from Kuzniak (2016b)

taking into account that sharing a written text with others can encourage discussion.

Throughout 2020, as a consequence of the pandemic, university classes across Chile were held in an online format and student participation is one of the issues that has emerged. Access and connectivity to attend virtual classes has been the first barrier. An average of $27 \%$ for the poorest quintile and $89 \%$ for the richest quintile of access to virtual classes in compulsory education has been reported (MINEDUC, 2020).

In higher education, no data have been reported yet. However, at the local level, little student participation in virtual classes has been detected. Somehow students do not feel committed to participate, where cameras and microphones turned off are the norm.

In this forced shift towards emergency virtual classes, in this article we analyze the epistemic arguments that may exist between students and a professor in the context of a virtual class supported by an online assessment system for a fraction task. In other words, technology appears as an element of communication between students and professors, and also as a support for mathematical activity. More specifically, the proposed research question is:

What is the work of argumentation generated in a virtual classroom in tasks on fractions assisted with technology?

\section{THEORETICAL FRAMEWORK}

We want to characterize epistemic discussions using the Mathematical Working Space (Kuzniak et al., 2016a; Kuzniak \& Richard, 2014) by decomposing them into the different geneses and planes offered by this theoretical framework.

The Mathematical Working Space (MWS) allows us to identify and analyze the mathematical work of a subject, in this case the discussions among peers and with the professor, taking into account epistemological and cognitive aspects of the subject addressed and of the solver, respectively. These aspects are articulated through the semiotic, instrumental and discursive geneses (see Figure 1). Here the word genesis is used in a broad sense and refers both to the beginning of a process and to its development and interaction between the epistemological and cognitive poles.

In our work, in order to identify the epistemic value of the discussions that are generated between peers and student-professor, we will identify the geneses that are activated in the arguments that are made. For this, it is essential to identify whether a mathematical object, such as a function or a formula, is used in the dialogue as a semiotic tool, a material or symbolic artifact or as a theoretical tool.

On the epistemological plane are the objects and/or tools that allow the mathematical work to be developed and three poles are defined: the representamen ${ }^{1}$, the artifacts and the theoretical referential. According to Kuzniak et al. (2016b), in the MWS model, mathematical objects can become tools or vice versa. On the other hand, on the cognitive plane, three processes are found, through which an attempt is made to account for mathematical activity: visualization, construction and proof.

It should be noted that, in order to identify the genesis that is activated or privileged in the resolution of a task, we need to identify in which of the three poles of the epistemological plane a particular mathematical object is located. The status of an object or tool, and its relation to the pole in which it is located, will be best determined by its use rather than by an intrinsic characteristic. Namely, we will say that a mathematical object or tool is at the pole of representation when it is used as a semiotic tool, in other words, when it is utilized the basis of its visualization and the relations between its figural units are taken into account, not only the visual perception that provides direct access to the object. Objects at the pole of material or symbolic artifacts will

1 The term representamen is not translated in order to preserve the meaning of the word (Pierce, 1932). 
be identified when working with material tools (such as a ruler and a compass), computer tools (such as a CAS calculator) or symbolic artifacts, such as an algorithm. For the first two cases, given their nature, they are easily identifiable, whereas the symbolic artifact will be identified when a mathematical object or an algorithm is used as a tool to obtain a result and its properties are not taken into account, i.e., when its use is not supported by the theoretical referential. Thus, we will associate the status of symbolic to a totally naturalized and routine use, in which its validity and justification are neither discussed nor questioned.

Finally, at the pole of the theoretical referential are the properties, theorems and axioms that support mathematical discourse. This pole should not be thought of only as a collection of properties, because as it supports deductive justifications, it must be organized coherently and well adapted to the tasks that students are asked to solve (Kuzniak et al., 2016b).

As Kuzniak et al. (2016a) point out, mathematics is first and foremost a human activity and not just a list of signs and properties. For this reason, this model considers a second level centered on the subject as a cognitive subject whose mental processes are in interaction with the epistemological plane through a specific mathematical activity. The three processes considered at the cognitive level are: visualization, construction and proof. Visualization is related to the interpretation of signs and the internal construction of the representation of objects and their relationships. Construction relates to the use of artifacts (material or symbolic), together with schemas of use to produce tangible items such as writings or drawings and also to artifact-mediated observation, exploration and experimentation. Finally, testing is related to the process of justification by theoretical tools and not only an empirical validation, which could be understood more as the construction process described above.

The epistemological and cognitive planes are articulated through three geneses: semiotic, instrumental and discursive.

The semiotic genesis connects the visualization process on the cognitive level with the representamen on the epistemological level. This genesis can start with the sign in the representamen that is interpreted by the subject through visualization. It can also start from the subject who encodes and produces a sign.

The instrumental genesis connects the construction process on the cognitive plane with the pole of artifacts. When working with material, computational or symbolic tools, this genesis involves two processes: instrumentalization and instrumentation (Coutat \& Richard, 2011). The first involves the emergence and evolution of the schemes of use of the artifact and the use of the possibilities offered by the artifact. The second one starts from the subject and is related to the emergence and evolution of the schemes of use and of the instrumented actions, their constitution, functioning, coordination, combination, inclusion and assimilation of new artifacts to already constituted schemes. Mathematical work could be considered routine if it is not connected to the validation and justification of artifacts.

Finally, the discursive genesis connects the proof process with the pole of the theoretical referential at the epistemological level and is associated with the process of deductive reasoning by means of theorems and properties. In the latter case, the focus is on properties and theorems, so we are thinking of reasoning that goes beyond visual or instrumental reasoning, but which can be triggered by them.

When it is not possible to distinguish which genesis is being privileged, the Mathematical Working Space can be characterized through the connection of two geneses, considering some of the three vertical planes: semioticinstrumental, semiotic-discursive or instrumentaldiscursive (Coutat \& Richard, 2011).

\section{DATA COLLECTION AND METHODOLOGY}

The present research is developed through a qualitative approach, given the nature of the phenomenon under study. According to Creswell and Poth (2009), qualitative research is an interpretative process of enquiry based on different methodological traditions that examines a human or social problem. From this perspective, and understanding that the problem is framed in the field of Didactics of Mathematics as a science, an enquiry that allows articulating a theoretical framework with specific procedures for data analysis is deemed appropriate. The analysis corresponds to a course to which access is available. The information is analyzed by means the thematic analysis (Boyatzis, 1998) where themes are generated deductively at both the manifest level and the latent level, in the dialogues of the class participants, including the professor. The themes are pre-established according to the categories offered by the MWS theory: semiotic, instrumental and discursive genesis and vertical planes, as shown in Table 1 . In order to consider the subjectivity of the researchers, the thematic analysis was of the reflexive type, so emerging themes are also identified during the study.

At the university where the study was carried out, the first-year students of Mathematics Pedagogy have a subject called ICT (Information \& Communication Technology) for learning mathematics. One of the proposed objectives was to encourage discussion and argumentation about different mathematical concepts using technological tools. This is a public university in Chile and has a long tradition of training mathematics teachers. 
Table 1. Deductively generated themes for analysis

\begin{tabular}{|c|c|c|}
\hline Theme code & Genesis and vertical planes & Description \\
\hline TG1 & $\begin{array}{l}\text { Activation of the semiotic } \\
\text { genesis }\end{array}$ & $\begin{array}{l}\text { we recognize this theme when different registers are used and articulated } \\
\text { to represent mathematical objects. }\end{array}$ \\
\hline TG2 & $\begin{array}{l}\text { Activation of the instrumental } \\
\text { genesis }\end{array}$ & $\begin{array}{l}\text { we recognize this theme when both technological and algorithmic tools } \\
\text { are used. }\end{array}$ \\
\hline TG3 & $\begin{array}{l}\text { Activation of the discursive } \\
\text { genesis }\end{array}$ & $\begin{array}{l}\text { we recognize this theme when discursive elements appear, such as } \\
\text { logical connectives, explanations or proofs }\end{array}$ \\
\hline TP1 & $\begin{array}{l}\text { Activation of the semiotic- } \\
\text { instrumental plane }\end{array}$ & $\begin{array}{l}\text { we identify this theme when different representations of objects are } \\
\text { articulated with technological or algorithmic tools }\end{array}$ \\
\hline TP2 & $\begin{array}{l}\text { Activation of the instrumental- } \\
\text { discursive plane }\end{array}$ & $\begin{array}{l}\text { We identify this theme when the discourse comes from the manipulation } \\
\text { of tools, or on the contrary, tools are manipulated based on } \\
\text { argumentative or evidentiary elements. }\end{array}$ \\
\hline TP3 & $\begin{array}{l}\text { Activation of the semiotic- } \\
\text { discursive plane }\end{array}$ & $\begin{array}{l}\text { we identify this theme when the representations or changes in the } \\
\text { registers are articulated with the argument the individual is constructing }\end{array}$ \\
\hline
\end{tabular}

A

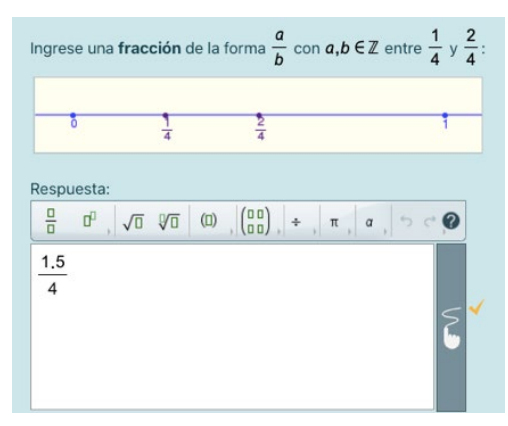

Translation:

Enter a fraction of the form $a / b$ with $a, b \in \mathbb{Z}$ between $1 / 4$ and $2 / 4$ :

Answer: $1.5 / 4$
B

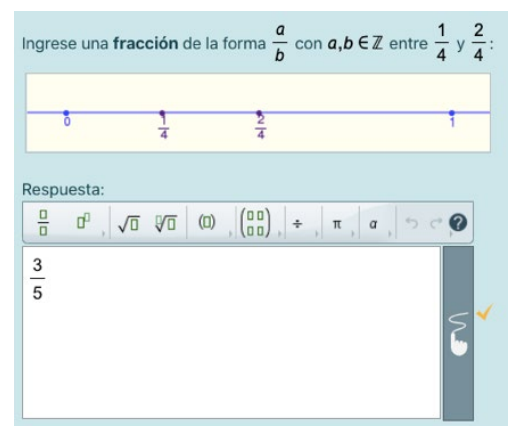

Translation:

Enter a fraction of the form $a / b$ with $a, b \in \mathbb{Z}$ between $1 / 4$ and $2 / 4$ :

Answer: 3/5
C

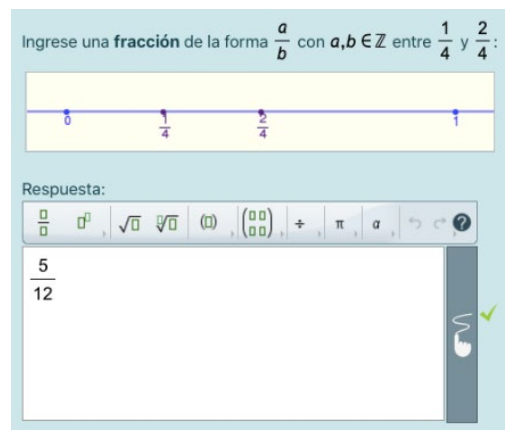

Translation:

Enter a fraction of the form $\mathrm{a} / \mathrm{b}$ with $a, b \in \mathbb{Z}$ between $1 / 4$ and $2 / 4$ :

Answer:5/12

Figure 2. Questions to be answered by each student.

A series of tasks were proposed on a Moodle platform (http://moodle.org) with the Wiris plugin (http://www.wiris.com), to which each student had access during the class, as all they needed was an internet connection. These tools made it possible to create tasks with infinite answers in order to encourage discussion. The tasks were implemented during the second semester of 2020, with 15 trainee teachers (in their first year of studies) who initially worked individually, answering on the platform for 10 minutes, followed by a discussion phase. The class, being virtual, was recorded and the passages where an epistemic discussion took place were transcribed.

In the questionnaire analyzed in this paper, each student had an individual (virtual) space where they had to give three different answers to the same task. Based on the work of Gaona (2020), the artifact-task in an online assessment platform is decomposed as follows:

- The statement, which in turn can identify the type of task and the mathematical objects Gaona et al. (2021), which consisted of entering a fraction of the form $a / b$, with $a$ and $b$ in the integers, that is between $1 / 4$ and $2 / 4$, together with a section of the real line where these values were located.

- The input system: an equation editor for entering the answers. Figure 2 shows some of the answers entered by the students.

- The validation system: which classified the answers as incorrect, partially correct and incorrect. The system scored the first answer (Figure 1A) as partially correct because the student entered a decimal in the numerator, and the instructions asked for whole numbers. The second answer (Figure 1B) was also scored as partially correct because the value entered is greater than $1 / 4$ but not less than $2 / 4$. Finally, the third answer (Figure 1C) is considered correct because it meets all the requirements. This implies that, due to the nature of the task and the conditions to be met, any number entered by the student will meet at least one condition, so the system will at least evaluate it as partially correct.

- The feedback system: once the student enters the answer, the system not only scores the answer as 


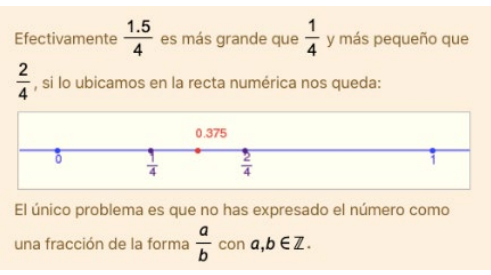

Translation:

Effectively $1.5 / 4$ is larger than $1 / 4$ and smaller than $2 / 4$. If we place it on the number line, we obtain:

0.375

The only problem is that you have not written the number as a a/b fraction with $a, b \in \mathbb{Z}$.
B

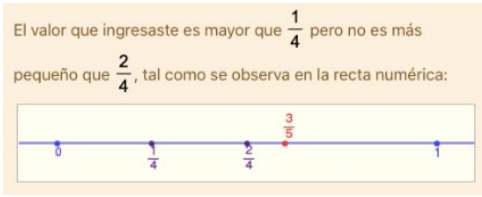

Translation:

The value that you entered is larger than $1 / 4$ but not smaller than $2 / 4$, as we can observe in the number line:

$3 / 5$
C

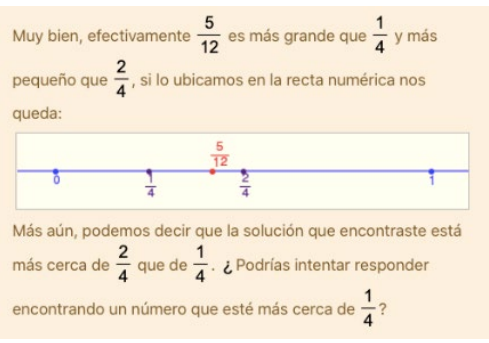

Translation:

Great! Effectively 5/12 is larger than $1 / 4$ and smaller than $2 / 4$. If we place it on the number line, we obtain:

$5 / 12$

Even more, we can say that the solution that you found is closer to $2 / 4$ than to $1 / 4$. Could you try answering by finding a number that is closer to $1 / 4$ ?

Figure 3. Questions to be answered by each student

Table 2. Average number of attempts, response rate Q1, Q2 and Q3 and average time (in minutes)

\begin{tabular}{lllll}
\hline Attempts & $\% \mathrm{Q} 1$ & $\% \mathrm{Q} 2$ & $\% \mathrm{Q}$ & time $(\mathrm{min})$ \\
\hline 1.3 & $80.8 \%$ & $91.6 \%$ & $92.0 \%$ & 6.3 \\
\hline
\end{tabular}

correct or incorrect, but also provides automatic feedback, which shows why the answers are considered as partially correct or incorrect. This is shown in Figure 3. In this feedback, the platform places the value entered on the number line and indicates whether it meets the rest of the conditions, i.e., the feedback does not give the answer or suggest any strategy on how to solve it, but provides an explanation about why what is done is correct or incorrect. Moreover, in the case of being correct, it invites the user to look for another value that is qualitatively different from the one entered, e.g., in Figure $2 \mathrm{C}$, the user is asked to enter a value closer to $1 / 4$.

In this case, the digital artifact contains a pragmatic and an epistemic component (Artigue, 2002). It has a pragmatic component because it automatically receives, records and scores the students' answer and it has an epistemic component because it issues a judgement of the student's answer (indicating whether it is correct or incorrect). Additionally, in the feedback, it places the student's answer on a number line, makes comparisons graphically and analyses the structure of the answer to indicate whether or not it complies with the requested format, thus giving meaning to the interaction that takes place.

Work was carried out in three stages:

- Class 1: individual work was done on the platform for 10 minutes where they had to find a fraction between $1 / 4$ and $2 / 4$. The rest of the class was spent discussing strategies and generalization of results. The class ended with the question: Can you find an infinite sequence of fractions between $1 / 4$ and $2 / 4$ ?

- Class 2: group work was done where they had to work on finding an answer to the question that was posed at the end of the previous class.

- Assessment: there was a virtual component where they had to find fractions between two other randomly given fractions and then, on paper, they had to find a sequence of infinite fractions that were between the fractions they had answered on the platform.

For the analyses, the professor's dialogues were coded with the letter P and the students' with the letter E plus a number to differentiate them: E1, E2, etc.

\section{RESULTS AND DISCUSSION}

\section{Class 1: Finding a Fraction Between Two Fractions}

\section{Individual work on the platform}

All 15 students entered answers. The average number of attempts, correct answers and time spent is summarized in Table 2.

The average number of attempts was 1.3 because there were 5 students who made 2 attempts and the rest made 1 attempt. Also, it can be observed that the rate of correct answers was high, i.e., the questions turned out to be easy for the students. In fact, the lower rate of the first attempt was rather due to instrumental difficulties, e.g., one student entered the answer and a sentence, which the system marked as incorrect. The average time 
taken also indicates that they were able to answer the question fairly quickly.

\section{Strategies reported by students}

This initially simple work allowed, in a second instance, the formulation of questions during the lesson, which were directed towards the elaboration of arguments about the different strategies used. When asked via chat or voice, two strategies appeared:

- 7 students indicated that they used decimals, i.e., they transformed fractions to decimals, found a decimal between the two values and then converted the number found into a fraction again.

- 3 students stated that they used amplification, i.e., they amplified $1 / 4$ and $2 / 4$ by different positive integers and from that found a value between the two.

- 5 students did not say which strategy they used.

Through an inductive process, they were asked how many fractions were obtained between $1 / 4$ and $2 / 4$ when amplifying by $2,3,4, \ldots$ and $n$. The students quickly conjectured that there are $n-1$ fractions between the two. They were asked to prove this conjecture and it was proposed to review it later.

The students were then asked to describe the procedure they had done with decimals, one student for example chose $0.3,0.26$ and 0.4 , which she transformed to fractions: $3 / 10,13 / 5$ and $2 / 5$ (she simplified them).

\section{Discussion work on the basis of an unplanned strategy}

Subsequently, the students were asked if anyone had used the decimals in a different way and E1 indicated that he had chosen them at random; he named: 3/10, 2/5 and $9 / 20$. The dialogue from this interaction is shown in Table 3 and Figure 4.

In this discussion it can be seen that student E1 uses trial and error as a strategy. The calculator is used as a digital artifact. In theoretical terms, we can evidence the partial activation of instrumental genesis (Kuzniak et al, 2016a), so we identify the occurrence of theme TG2. We say partial, because the work does not start from the instrumentalization of the artifact that is put into use, but rather, it is an artifact that is associated with the action of corroborating whether the numbers established are valid

Table 3. Moment 1, an attempt is made to make explicit a strategy defined by the student as "random"

110. Q: 9/20, how did you find it? Because it is different from the ones that were here [referring to the ones previously found by his partner].

111. E1: I started to amplify, i.e. I started to increase the numerator, so I also increased the denominator until I got a fraction.

112. P: I want you to explain what you are saying, what do you mean by....?

113. E1: I mean, I started to try with numbers, I started to play with numbers and... I started to try with all of them $1,2,3, \ldots, 7,8$, 9... I started dividing by numbers, to see if they would give me...

114. Q: Yeah, so, for example, did you try with other denominators? How did you decide if the denominator you had chosen didn't work?

115. E1: Because I looked at it with the calculator (laughs)

116. Q: Give me an example, I want you to explain the process you went through, before 20, do you remember what number you chose?

117. E1: Number 5 I think

118. Q: You calculated 9/5, is that right?

119. E1: Yes, but that's 1.8, it's a lot, let's see with a very big denominator, for example 10.

120. Q: And how much did that give you?

121. E1: 0.9, it didn't work either, then I chose 15 as a parameter, because if it was too close, I knew I could try between those two new numbers [] then 20 [the denominator chosen] which is 0.45 .

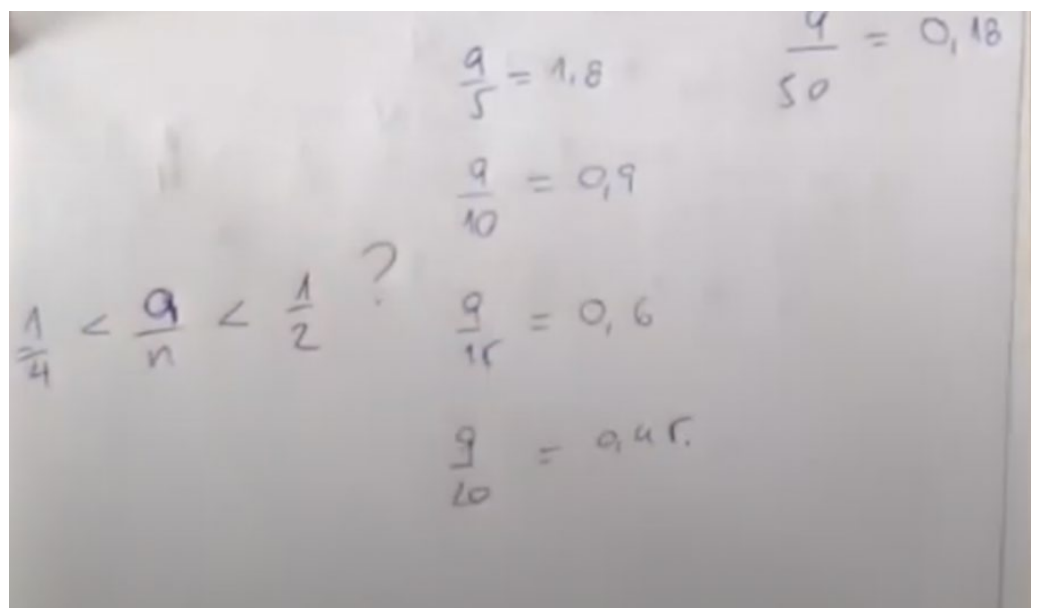

Figure 4. The professor writes what student E1 reports between lines 110 to 121, and also writes the question indicated in lines 122 and 126 of Table 4 
Table 4. Moment 1, an attempt is made to make explicit a strategy defined by the student as "random"

122. Q: If you make this number as big as you want [referring to the denominator], is it always in the interval?

123. E1: I think so.

124. P: For example, think of a large number

125. E1: $9 / 50$ is 0.18 it's not in [the range]

126. Q: What number can you divide 9 up to? Is $9 / \mathrm{n}$ smaller than $2 / 4$ and bigger than $1 / 4$ ? Can someone give me the answer to that?

[the professor writes down part of what the students report and the questions he asks].

127. E2: [after 20 seconds] between 36 and 18.

128. Q: How do you get that 36 and 18 ?

129. E2: I can raise the whole fraction to minus 1 and the symbols turn around.

130. P: The professor writes that on the projected sheet and asks what happens to the symbols?

131. E2: They are inverted and I amplify everything by 9.

132. P: And that leaves $36>n>18$ do you agree? why is this inequality inverted?

133. E1: It is multiplied by a negative number.., I mean, I don't know why...ah yep, it is turned around because it multiplied by 1

134. P: It didn't multiply by -1 , it raised to -1

135. E1: Ah ok, then I don't know why.

136. P: The question is, I'm going to put it this way: If $a<b$ then $1 / a>1 / b$ ?

137. E3: Yes, I think so.

138. Q: So, this is true for all a, b in R (the reals)? How could you prove it? [...] how do you prove it? If it is true what your classmate did before (I'm going to show you) that what is there is true or we would know in which cases we can use it. Any ideas?

139. E4: Inaudible, [the students indicate that they can barely hear and E4 indicates that he will write via chat instead].

140. E4 (via chat): It could be done by eliminating the fractions // that is, by passing a and $b$ to their opposite sides.

141. E1: Can't you multiply across?

142. E4. What they just said haha

143. P: Can you multiply across? That is, by passing a and $b$ to their opposite sides. You say (write $a<b$ )

144. E2: Professor, I already proved it

145. Q: Which one, this one or the previous one?

146. E2: Both.

147. P: Wait a little bit to see if the argument that your classmates are using or thinking about is the same as the one you are going to use, if it is different, fine, if it is the same, tell me if you agree or not. If $a<b$ what operation should I apply to both sides of the inequality?

148. E5: By $1 / \mathrm{a}$ and then $1 / \mathrm{b}$.

149. E6: To eliminate denominators.

150. E7: Raise to -1 and invert the inequalities?

151. E2: That's what we want to show.

152. P: But that's what we want to prove, remember that's how this started, I raise it to minus 1 and the inequality is inverted.

153. E7: Oh! I had not realized that

154. Q: Do you agree that proving " $a<b$ then $1 / a>1 / b$ " is equivalent to proving "if $a<b$ and I raise to minus 1 then the inequality is inverted"?

155. E1: If we equal to zero? if $a<b$ then $a-b<0$ ?

156. Q: Between this step and the other step, what operation was there?

157. E7: -b

158. E1: The additive inverse was added.

159. Q: Why do I know that the inequality holds? What axiom am I using? What axiom of order allows me to do this step here?

160. E2: I multiply $a<b$ by $1 /(a b)$ with a and $b$ positive, so I make sure that I don't reverse the inequality.

161. Q: You assumed that $\mathrm{a}$ and $\mathrm{b}$ are positive.

162. E2: Yes, I restricted them and that leaves $1 / \mathrm{b}<1 / \mathrm{a}$ is for the positive reals.

163. P: That's what you wanted to prove.

164. E2: But only for positive reals

165. Q: Exactly, the result is not for all $\mathrm{R}$, is it? are there other numbers for which this is true?

166. E6: Professor, isn't it for when a and $b$ have the same sign? if $a$ and $b$ are negative then the multiplication is also positive and they have to be non-zero.

167. E1: If it is possible in the positive and negative reals, then is it possible in all the reals? or not?

168. E6: It should be in all the reals as long as they have the same sign.

169. P: So it's not for any pair of reals, if either is 0 , is it?

or not to satisfy the statement of the question that was posed. In this discussion, the student is trying to make explicit, on the basis of the professor's questions, what his procedures were.
The professor, based on the student's account of the trial-and-error strategy, asks questions (lines 122 and 126 of Table 4) that change the focus of the discussion. Now 
Table 5. Transcription of the proof of the conjecture: if I amplify the numerator and denominator of $1 / 4$ and $2 / 4$ by $n$, I get $\mathrm{n}-1$ fractions between them

170. Q: E2 told us that he had proved the other conjecture. That if we have 1/4 and 2/4 and I amplify it by $n$ then there are $n-1$ fractions between the two numbers and E2 said he proved it. Do you want to show it?

171. E2: Professor I did it in Paint

172. [P: explain to us what we are seeing (E2 is demonstrating that when you amplify by $n$ you get $n-1$ fractions between the two).

173. E2: I defined how many fractions... wait, I got confused.

I put the fractions one by one between $n / 4 n$ and $2 n / 4 n: n / 4 n, n+1 / 4 n, \ldots,(2 n-1) / 4 n, 2 n / 4 n$ and counted all the fractions that there were.

To count them I subtracted this numerator here [referring to $2 n-1$ ] and this numerator here [referring to n] and I got 2n-1-n and I got n-1.

174. Q: The demonstration is very good, does anyone have any comments?

175. E2: I put all the fractions between $n / 4 n$ and $2 n / 4 n$ and then I counted them by calculating $2 n-1-n=n-1$.

the values for which $9 / \mathrm{n}$ are between $1 / 4$ and $2 / 4$ are sought.

E2, in line 129, states that "raising the fraction to minus 1 turns the inequality around". In this sentence we can see that his argument is based on a routine scheme, in which he does not make a property explicit, so we qualify his justification as instrumental.

The professor asks what are the properties that justify the inequalities to be reversed. In other words, there is again a change of focus. If we first sought to make the strategies explicit, then to find all the values of $\mathrm{n}$ that satisfied $1 / 4<9 / n<2 / 4$, we now seek, between lines 129 and 169 , the justification of this solution. It is observed that there are erroneous arguments, like the one in line 133 where E1 says that it multiplies by -1 or circular arguments like the one in line 140 given by E4: "it could be done by eliminating the fractions / / that is by passing $\mathrm{a}$ and $\mathrm{b}$ to their opposite sides (written by platform chat)", the one in line 141 given by E1: "can't one cross multiply?", E7 in line 150: "it is raised to -1 and the inequalities are inverted?". Finally, between lines 155 and 169 the justifications are based on the theoretical referential, students evoke the axioms and order properties of real numbers. If one compares the arguments used before line 155, one observes a transition from the instrumental to the discursive, students go from using symbolic artifacts such as "cross multiplication" or "they invert" to properties of the theoretical referential, even, unlike what is observed in the use of symbolic artifacts, they are concerned with the domain of validity of the proposition constructed. Specifically, the validity of the statement is extended beyond what is needed to justify the solution of the inequality.

In this process it is observed that it is the professor who is validating the students' arguments through counter-questions. Up to this point, the students are not yet autonomous in determining the validity of their claims.

Subsequently, the students were asked if anyone had used the decimals in a different way and E1 indicated that he had chosen them at random; he named:3/10, 2/5 and $9 / 20$. The dialogue from this interaction is shown in Table 3 and Figure 4.
In this discussion it can be seen that student E1 uses trial and error as a strategy. The calculator is used as a digital artifact. In theoretical terms, we can evidence the partial activation of instrumental genesis (Kuzniak et al., 2016a), so we identify the occurrence of theme TG2. We say partial, because the work does not start from the instrumentalization of the artifact that is put into use, but rather, it is an artifact that is associated with the action of corroborating whether the numbers established are valid or not to satisfy the statement of the question that was posed. In this discussion, the student is trying to make explicit, on the basis of the professor's questions, what his procedures were.

Then the professor summarizes the elements given by the students and corroborates for $\mathrm{n}=21$ : if $\mathrm{n}$ is greater than 18 and less than 36 then $9 / 21=3 / 7$, which is between $1 / 4$ and $2 / 4$. First, he does this by asking them to calculate its decimal value and then asks them to prove that it is between the requested values, without using decimals. In the calculations, the least common multiple appears, which was first obtained by means of a table (symbolic artifact) and then by prime decomposition. In this episode we again see a transition from the instrumental to the discursive about the order of fractions.

Next, a conjecture made at the beginning of the class is taken up again and E2 demonstrates it, which is transcribed in Table 5. The student uses a sequence written in algebraic form to demonstrate (Figure 5). The argument is transcribed in line 173. On the right-hand side, in Figure 5, we can also see the demonstration discussed between lines 122 and 169 .

At the end of the class, the professor poses the following question: how do we find infinite fractions between $1 / 4$ and $2 / 4$ ?

We schematize what happened in class 1 in Figure 6. The diagram shows how the students move from the use of non-classical material artifacts (calculator) to the use of symbolic artifacts (algorithms). Then, their arguments progress by evoking the theoretical referential (with the use of properties on real numbers). Thus, an articulation is constructed between the instrumental and discursive geneses, that is to say, an activation of the instrumental- 


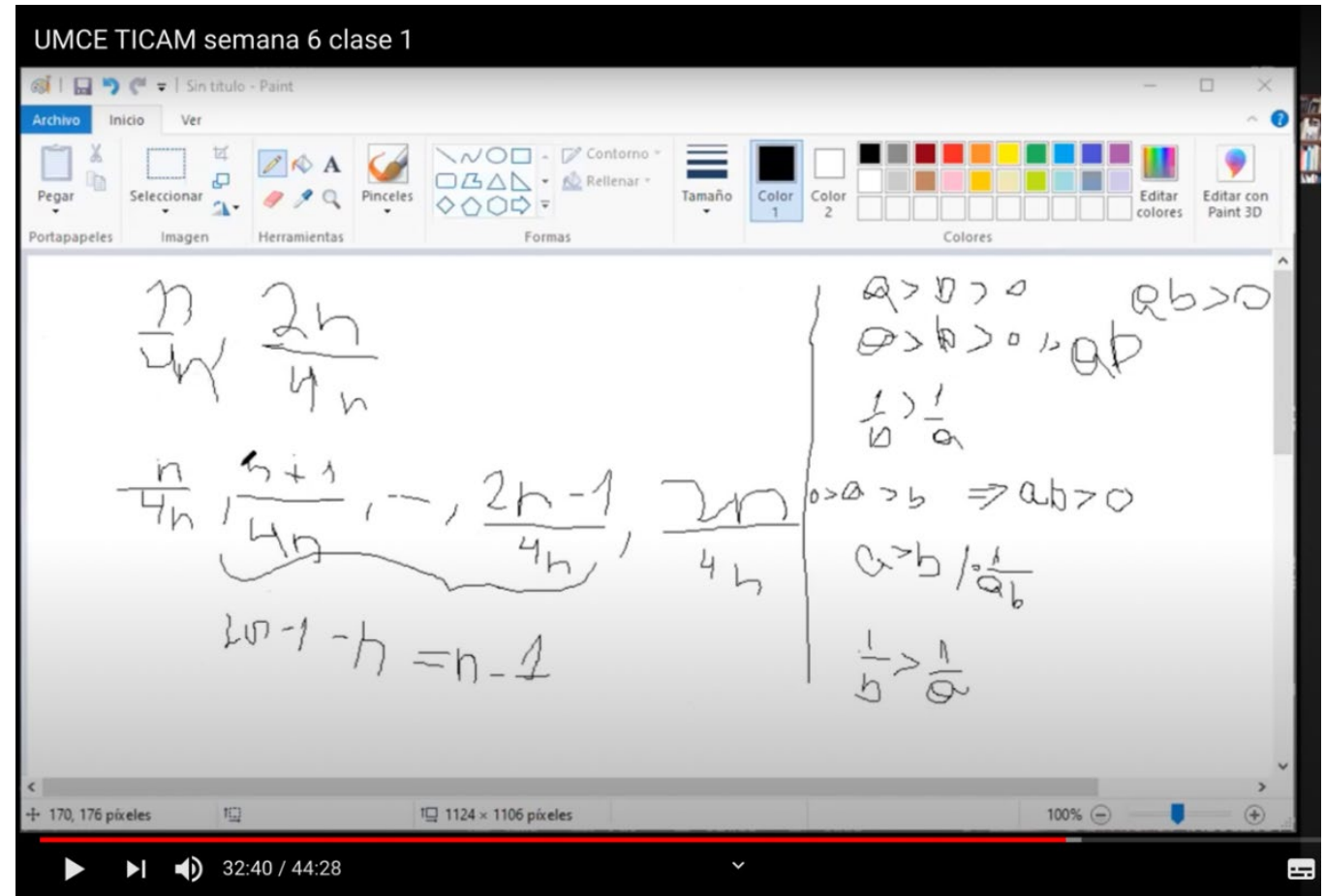

Figure 5. Screen shared by E2 explaining the demonstration of the conjecture raised

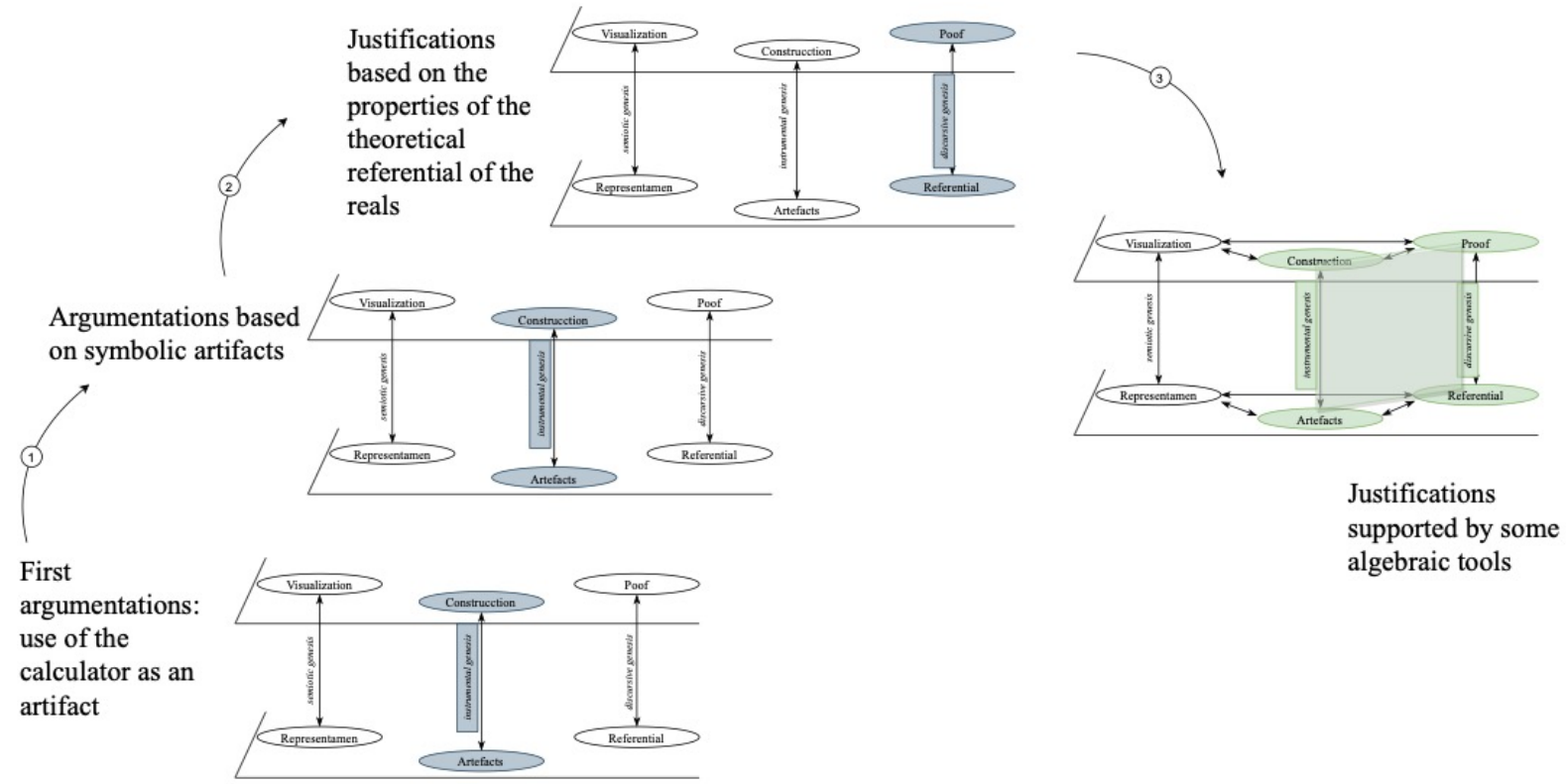

Figure 6. Schematic of the MWS from the discussion on the strategies used by students to find a fraction between $1 / 4$ and $2 / 4$

discursive vertical plane. This is because of a coordination is observed between processes that refer to the use of artifacts, with arguments based on properties of the theoretical referential.

\section{Class 2: Infinite Fractions Between 1/4 and 2/4}

The second lesson addressed the question posed in the previous lesson. Sixteen students participated and the course was divided into three groups.

\section{Group work}

Student E1 of the first group explains in line 178 how he constructed the sequence (Table 6). First, he found a sequence bounded between 1 and 2, and then divided it by 4 to fit the requested interval. In this example, the formula if $\mathrm{a}<\mathrm{a} \_\mathrm{n}<\mathrm{b}$ and $\mathrm{k}>0$, then $\mathrm{ka}<\mathrm{ka} \_\mathrm{n}<\mathrm{kb}$, is used implicitly. We can classify this argumentation in the instrumental-discursive plane because it is justified, but it is not clear to what extent the student is aware of the properties he is using in his argumentation. It is observed that the sequence obtained is decreasing and converges to $1 / 4$, but this is not mentioned. The professor, together with the students, carries out a verification work with different numbers where the sequence is fulfilled. Besides, they show that, for some values, the sequence that is in the required interval is not 
Table 6. Transcript of the work done by group 1. One student found a sequence and his classmates tried to understand if it worked and why

178. E1: What I understood is that you had to find a general formula for numbers between $1 / 4$ and $2 / 4$. The first thing I did was to find one that is between 2 and 1 and I divided it into 4 , which would be $(n+1) / n$, then I divided it into 4 and it was (n+1)/4n is between $1 / 4$ and $2 / 4$.

179. E2: I understood the first part, but I didn't understand why it is divided by 4.

180. P: First let's see if what your partner says is true: $(n+1) / 4 n$ is between $1 / 4$ and 2/4? I want E2 and E3 to answer.

181. E3: If we replace by 1 it would have to be between the values

182. P: You say if $n=1$ how much is left in the middle expression?

183. E3: $2 / 4$ which is the same as $1 / 2$ and does not satisfy

184. P: Let's try other numbers because what matters is that there are infinite numbers that work. If $n=2$, how much is left?

185. E3: 3/8

186. Q: Does it work?

187. E3: Yes, you can check it by multiplying across.

188. Q: Let's try a slightly larger number: $n=7$, how much is left?

189. E3: $8 / 28$

190. P: Will it be less than $2 / 4$ and greater than $1 / 4$ ?

191. E3: It works

192. Q: Do these three examples help me to prove that this expression is always between $1 / 4$ and $2 / 4$ ?

193. E2: It's just that there are only a few numbers.

194. Q: If I try 10 and it works, would that be sufficient?

195. E3: Multiplying the number that we use in $n$ will give us a number that is smaller than this one because it is getting smaller. 196. P: Even if we try 100, 1000 or even a million, it is not enough to prove that they are all there, we need that kind of argument, a bit more specific to prove that they are all there. Think about that, I'll join another group that's calling.

Table 7. Transcript of professor's discussion with group 2

197. E4: Professor, we don't understand anything, we are lost.

198. E5: Yes professor, we don't know how to do it.

199. P: Let me see other students who are outside the small groups and I'll come back.

220. P: Don't you know how to do it or don't you understand the problem?

201. E5: I understand the problem, but I don't know how to do it, I thought about summations, but I don't remember.

202. Q: It's simpler than that, I'll give you an idea so you can move on: think about $1 /(n+2)$. If $n=1,1 / 3$ is between $1 / 4$ and $1 / 2$ ?

203. E6: Yes

204. $P$ : If $n=2,1 / 4$ is between $1 / 4$ and $2 / 4$.

205. E4, E5 and E6: no

206. P: This sequence is infinite, but it goes out of the interval, you should look for one that works for you, you can even use Excel to try it out.

Table 8. Transcript of professor's discussion with group 3

207. E7: We found one, but it was restricted.

208. Q: How restricted?

209. E7: Only for natural numbers.

210. P: But it works, natural numbers are infinite. I would have to see how you proved that it was between $1 / 4$ and $2 / 4$.

211. E8: We tried with many numbers

212. E7: But that's not proving, that's showing.

213. E8: We tried with high numbers, with the million, with the 100 , we tried with big and small numbers.

214. Q: Did you try them all?

215. E7: How are we going to try them all?

216. P: I'm not convinced by your argument, as you tested large and small numbers, that gives you some confidence that it seems to work, but as you haven't tested them all [...] that's what you have to prove.

217. E7: I know, professor, we'll call you when it's ready.

sufficient to demonstrate that all the values of the sequence (starting from a specific $\mathrm{n}$ ) are in the interval. This difference is not clear for the rest of the students in the group.

Group 2 (Table 7) says that they do not know how to approach the problem. In contrast, group 3 (Table 8) indicates that they did find one, they showed that they proved that it worked because they evaluated in large and small numbers. In a way they use what Balacheff
(2000) calls "crucial example" (p.26) because they seek to test generalized examples. In the dialogue it is evident that the justification presented is produced through the activation of the instrumental-discursive vertical plane, where the instrumental process occurs through the evaluation of large numbers in the constructed sequence. The professor indicates to them that although, from these trials, they can have some certainty of their results, this does not imply that this procedure can be considered as a mathematical proof. 
Table 9. Transcript of group discussion, during class 2, on the infinite sequences found after working in groups

218. Q: E1 can you show the sequences you found?

219. E1: I don't have them together. There is the other sequence $(2 n-1) / 4 n$ and the demonstration for greater than or equal to $1 / 4$ came out wrong.

220. P: Show it anyway because, although it is not right, it can give clues to your classmates to try to prove it, because what was proved is that $(2 n-1) / 4 n$ is greater than $1 / 4$ and if you multiply everything by $1 / n$ it is not greater than $1 / 4$. And what about the other one you found?

221. E1: The other one, the demonstration is this (shows Figure 7(c)) and the other one you have (the professor makes a transcription of what E1 said and shows it in Figure 7(c)).

222. Q: The interesting thing about this sequence is that it has infinite values that lie between $1 / 4$ and $2 / 4$. Another group proposed the sequence $(2 n-1) / 4 n$, about that sequence there are several questions: is it between $1 / 4$ and $2 / 4$ ? is it increasing, because that's what your classmate said?

223. E7: I showed that the second sequence I had put was increasing.

224. Q: Can you show the demonstration?

225. E7: I didn't put in writing what I did but what I did was to use the definition that the difference between a_n+1 minus a_n has to be greater or less than zero. If it is greater it is increasing, if it is less it is decreasing, so it gave me a positive number therefore, it is increasing (see Figure 8).

226. Q: We'll finish the class now, we're a bit over time, see you next week.
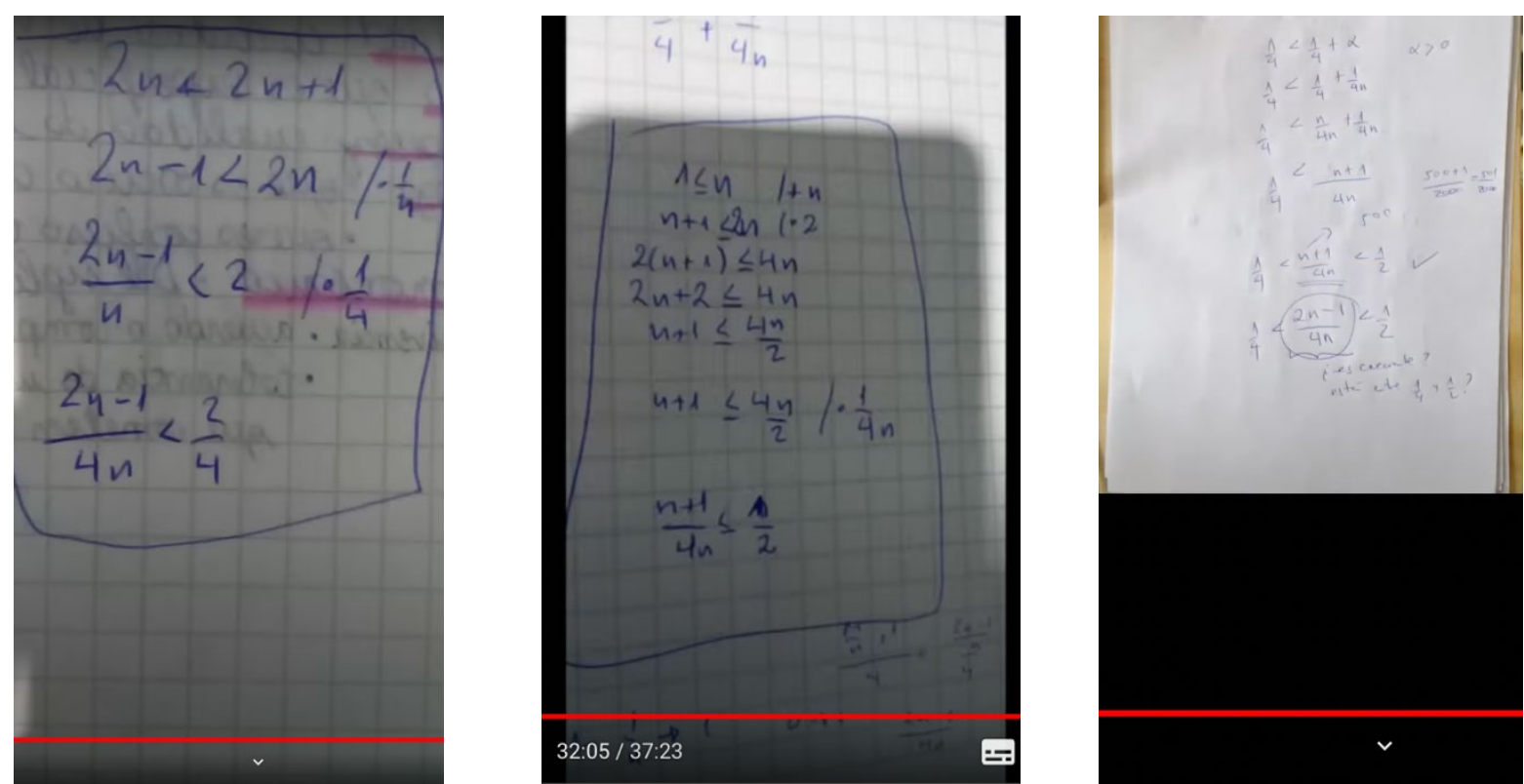

Figure 7. Demonstration by E1 in class 2 to justify that the sequences found are bounded between 1/4 and 2/4

\section{Collective discussion}

Afterwards, there is a collective discussion about the sequences found. Only 3 sequences appear, two from group 1 and one from group 3, all described in Table 9. The ones found by group 1 are $a_{-} n=(2 n-1) / 4 n$ and b_n $=(n+1) / 4 n$, although both sequences work, E1 could only show that a_n was not greater than $1 / 4$. This student used properties of the reals to narrow down the sequence and demonstrate what he had done, as shown in Figure 5. Also, E7 from group 3, applying the definition, demonstrates that the sequence is increasing (see Figure 7).

In both demonstrations, unlike what was done at the beginning of class 1 , it can be observed that the students look for the properties and definitions that justify their propositions, i.e., this work is more oriented towards a discursive genesis, identified in theme TG3.

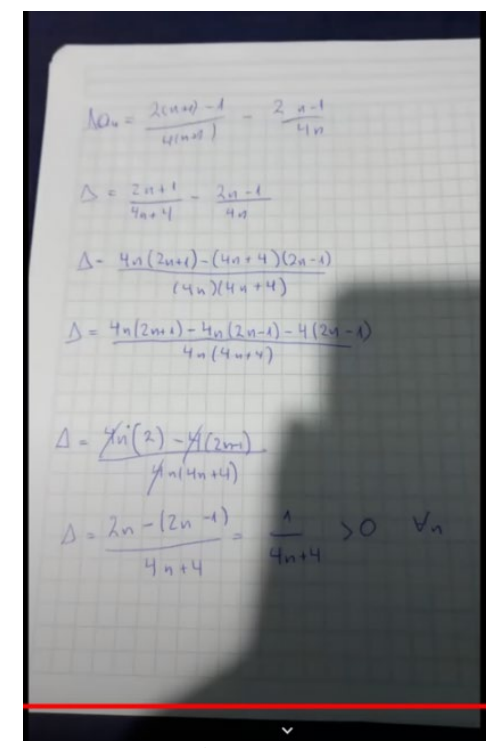

Figure 8. Demonstration that a sequence is increasing 


\begin{tabular}{|c|c|c|c|c|c|}
\hline & A & B & C & D & $\mathrm{E}$ \\
\hline 1 & $\frac{1}{11}<\frac{N+1}{11 \cdot N}<\frac{2}{11}$ & $\frac{2}{5}<\frac{2 n+1}{5 n}<\frac{3}{5}$ & $\frac{1}{4}<\frac{\mid n+1}{4 n}<\frac{2}{4}$ & $\frac{5}{8}<\frac{5 n+1}{8 n}<\frac{3}{4}$ & $\frac{6}{11}<\frac{26 n+1}{44 n}<\frac{7}{11}$ \\
\hline 2 & $\frac{1}{8}<\frac{N+1}{8 v}<\frac{1}{4}$ & $\frac{5}{8}<\frac{5 n+1}{8 n}<\frac{3}{4}$ & $\frac{5}{8} \leqslant \frac{5 m+t}{8 m_{1}} \leqslant \frac{6}{3}$ & $\frac{1}{4}<\frac{2 n+1}{8 n}<\frac{3}{8}$ & $\frac{1}{5}<\frac{6 n+1}{20 n}<\frac{2}{5}$ \\
\hline 3 & $\frac{3}{7}<\frac{3 N+1}{7 N}<\frac{4}{7}$ & $\frac{4}{10}<\frac{4 n+1}{10 n}<\frac{1}{2}$ & $\frac{4}{7} \leq \frac{4 m+1}{7 m} \leq \frac{5}{7}$ & $\frac{3}{11}<\frac{3 n+1}{11 n}<\frac{4}{11}$ & $\frac{2}{7}<\frac{10 n+1}{28 n}<\frac{3}{7}$ \\
\hline 4 & $\frac{5}{11}<\frac{5 n+1}{11_{n}}<\frac{6}{11}$ & $\frac{5}{9}<\frac{5 n+1}{9 n}<\frac{2}{3}$ & $\frac{1}{9}<\frac{1}{9}+\frac{1}{9 n}<\frac{2}{9}$ & $\frac{7}{11}<\frac{7 n+1}{11 n}<\frac{8}{11}$ & $\frac{3}{10}<\frac{14 n+1}{40 n}<\frac{2}{5}$ \\
\hline 5 & $\frac{6}{11}<\frac{6 \cdot n+1}{11 n}<\frac{7}{11}$ & $\frac{3}{11}<\frac{3 n+1}{11 n}<\frac{4}{11}$ & $\frac{4}{9} \leq \frac{4 m+b}{3 m} \leq \frac{5}{9}$ & $\frac{2}{11}<\frac{2 n+1}{11 n}<\frac{3}{11}$ & $\frac{2}{7}<\frac{10 n+1}{23 n}<\frac{3}{7}$ \\
\hline 6 & $\frac{8}{11}<\frac{8 n+1}{11 n}<\frac{9}{11}$ & $\frac{2}{11}<\frac{2 n+1}{11 n}<\frac{3}{11}$ & $\frac{2}{5}<\frac{2 n+1}{5 n}<\frac{3}{5}$ & $\frac{6}{8}-\frac{1}{8 x}$ & \\
\hline 7 & $\frac{1}{4}<\frac{2 n+1}{8 n}<\frac{3}{8}$ & $\frac{1}{8}<\frac{1 n+1}{8 n}<\frac{1}{4}$ & $\frac{5}{9}<\frac{5 n+1}{9 n}<\frac{2}{3}$ & $\frac{1}{6}+\frac{1}{6 x}$ & \\
\hline 8 & $\frac{1}{4}<\frac{1 n+1}{4 n}<\frac{1}{2}$ & $-\frac{1}{9}<\frac{n+1}{9 n}<\frac{2}{9}$ & $\frac{2}{9}<\frac{2 n+1}{9 n}<\frac{1}{3}$ & $\frac{1}{5}+\left(\frac{1}{5}\right)^{x}$ & \\
\hline 9 & $\frac{2}{9}<\frac{2 n+1}{9 n}<\frac{1}{3}$ & $\frac{2}{11}<\frac{2 n+1}{11 n}<\frac{3}{11}$ & $\frac{1}{8}<\frac{1 n+1}{8 n}<\frac{1}{4}$ & & \\
\hline
\end{tabular}

Figure 9. Summary of all sequences found by students

\section{Evaluation of the Sequence}

Finally, there was an evaluation that had an individual component on the platform with automatic correction and a group component that they had to send in a hand-written or written in LaTex that was corrected manually. Seventeen students took part in this assessment, two more than those who attended the first class. All of them gave more than one example, so there are more answers than the number of students.

When summarizing all the sequences found by the students, in Figure 9, a pattern is observed: the answers between A1 and D5 (32 answers) build from a1/b1 and $a 2 / b 2$, the sequence $a 1 / b 1+1 / b 1^{*} n$. All the sequences that are constructed are decreasing and convergent to a1/b1.

The second group of answers corresponds to the three sequences between D6 and D8. In this case, students choose a different letter for the independent variable. They constructed three sequences. The first one is an increasing sequence converging to the largest value of the interval, in this case $6 / 8$. The second is a sequence like the one of the first group, i.e., increasing and converging to the smallest value, in this case $1 / 6$. The third and last sequence is also increasing, but it is a sequence that is formed by a power of the smallest value.

The third group corresponds to the sequences in column E, which are all sequences convergent to the center of the interval.

\section{Justifications of the first and third group of sequences}

The justifications of group 1 are proofs that follow the same scheme. First, they show that $a 1 / b 1$ is less than $a 1 / b 1+1 / n^{*} b 1$, then they leave the sequence of the form

$$
\begin{aligned}
& \text { Busquan une secuencia infinte de frecciones... } \\
& \text { P1- } \frac{6}{11} ; \frac{7}{11} \\
& \frac{6}{11}<\frac{6 n+1}{11 n}<\frac{7}{11}, \forall n>1 \in W \\
& \text { Demestreción... } \\
& \frac{6}{11}<\frac{6}{11}+\frac{1}{11 n} \\
& \frac{6}{11}<\frac{6 n}{11 n}+\frac{1}{11 n} \\
& \frac{6}{11}<\frac{6 n+1}{11 n} \\
& \mid \begin{array}{c}
1<n \quad \mid+6_{n} \\
6_{n}+1<7 n \quad \mid \cdot\left(\frac{1}{11 n}\right)
\end{array} \\
& 0 \quad \frac{6 n+1}{11 n}<\frac{7 n}{11 n} \\
& \frac{6 n+1}{11 n}<\frac{7}{11}
\end{aligned}
$$$$
\text { Luy?, }
$$

$$
\frac{6}{11}<\frac{6 n+1}{11 n}<\frac{7}{11} ; \forall n>1 \in \mathbb{N}
$$

Figure 10. Summary of all sequences found by students

$\left(n^{*} a 1+1\right) / n^{*}$ b1 which is the answer presented. Then in a second part they construct, by means of equivalent inequalities, the upper bound (see Figure 10). If we analyze it at the individual level, we could classify the demonstration at the discursive level, but if we analyze it at the global level, taking into account that most of the students used the same argument, adapting it to their sequence, we could conclude that these arguments are at the instrumental-discursive level. Somehow, the procedure to demonstrate is instrumentalized and becomes a symbolic artifact, probably through a process of collective discussion. 
(c) Demuestre que esa secuencia está en los intervalos que corresponden.

Resp. Si graficamos en Geogebra la secuencia nos damos cuenta que para el primer término nos da $\frac{5}{8}$ y los demás términos tendrían límite $\frac{6}{8}$ ya que la secuencia se puede ver como una constante.

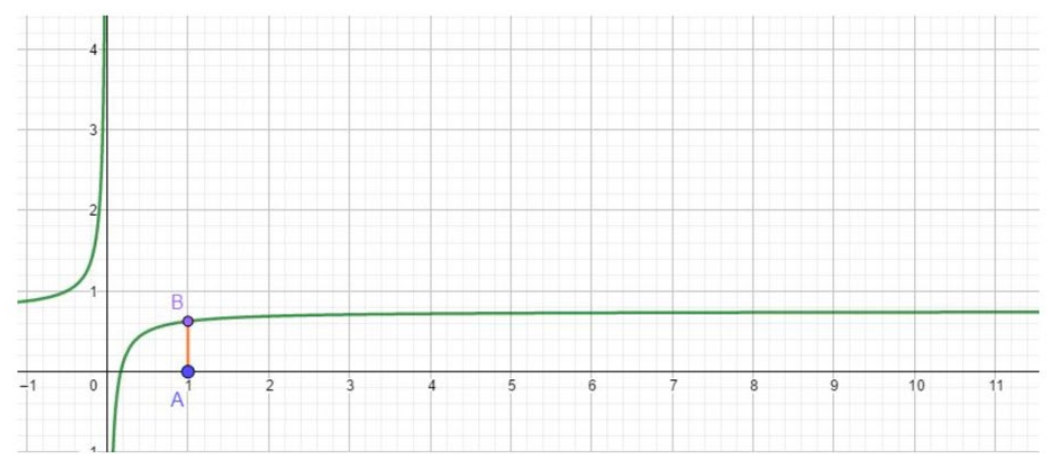

Translation: c) Demonstrate that that sequence is in the corresponding intervals

Answer: If we graph the sequence in GeoGebra, we realize that for the first term, we obtain 5/8 and the rest of the terms would have $6 / 8$ as a limit, because the sequence can be seen as a constant.

Figure 11. Justification of response D6

Justification based on inequalities
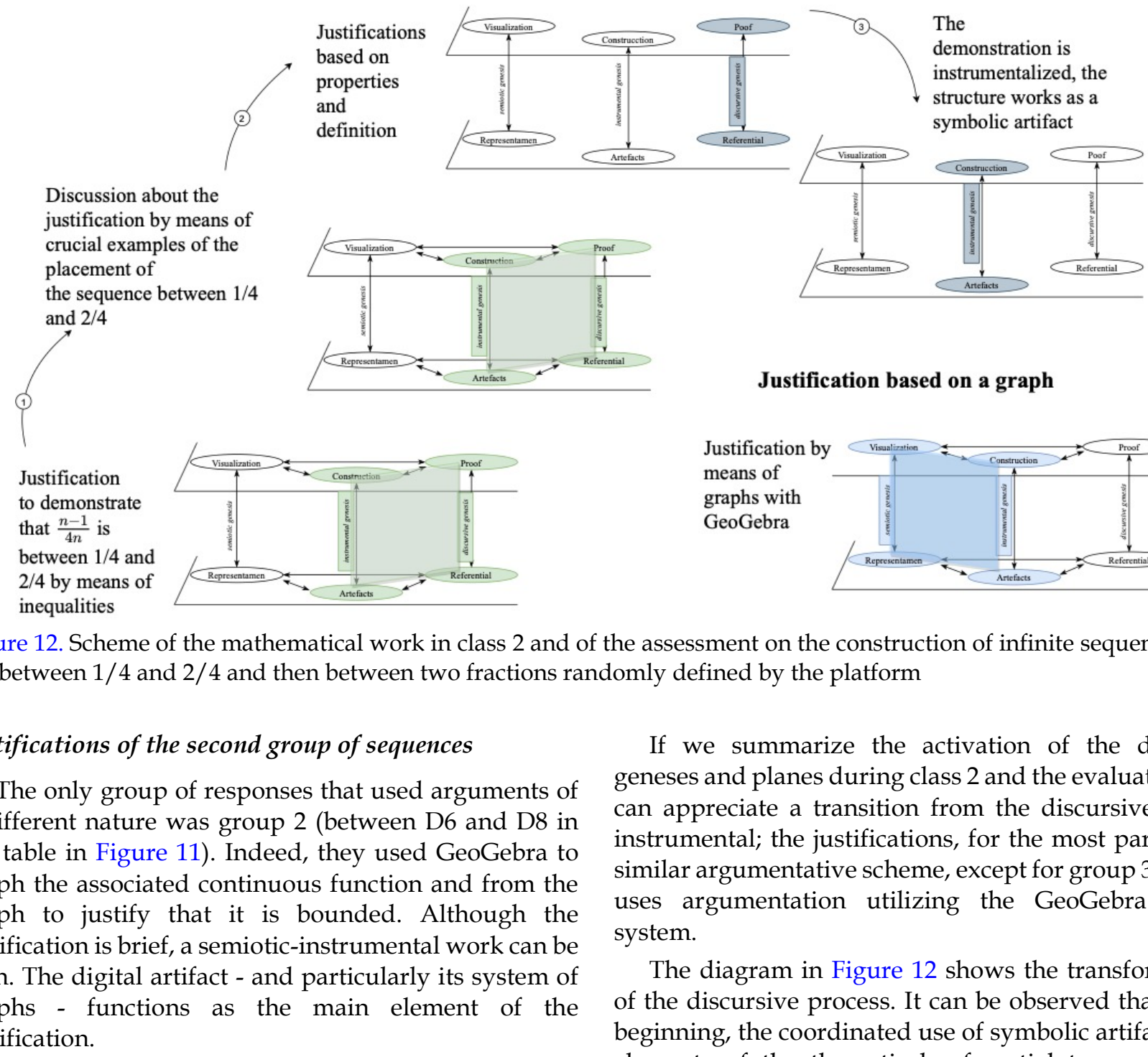

Justification based on a graph

Figure 12. Scheme of the mathematical work in class 2 and of the assessment on the construction of infinite sequences that are between $1 / 4$ and $2 / 4$ and then between two fractions randomly defined by the platform

\section{Justifications of the second group of sequences}

The only group of responses that used arguments of a different nature was group 2 (between D6 and D8 in the table in Figure 11). Indeed, they used GeoGebra to graph the associated continuous function and from the graph to justify that it is bounded. Although the justification is brief, a semiotic-instrumental work can be seen. The digital artifact - and particularly its system of graphs - functions as the main element of the justification.
If we summarize the activation of the different geneses and planes during class 2 and the evaluation, we can appreciate a transition from the discursive to the instrumental; the justifications, for the most part, use a similar argumentative scheme, except for group 3, which uses argumentation utilizing the GeoGebra graph system.

The diagram in Figure 12 shows the transformation of the discursive process. It can be observed that at the beginning, the coordinated use of symbolic artifacts and elements of the theoretical referential to construct a 
justification, causes the activation mainly of the vertical instrumental-discursive plane, except for one answer that activates the semiotic-instrumental plane. Subsequently, demonstrations are constructed, which shows an enrichment of the discursive genesis in relation to what was observed in the first class. Finally, the arguments of the demonstrations are instrumentalized, as they are subsequently used by almost all the students to respond to new tasks in a similar way. Here we can notice that there is an articulation between TP2, TP2, TG3 and TG2, in that order. In addition, there is a justification based on a graph, where the articulation between registers and technological tool is presented, work that we place in the TP1 theme.

\section{CONCLUSIONS}

During the virtual classes held during 2020, little student participation was observed; interventions were scarce, and most of the time the cameras and microphones were turned off (Peña et al., 2021). Among the initiatives adopted by professors for the training of future teachers, they began to develop open questions with infinite solutions, with automatic correction and feedback, with the aim of encouraging discussion of strategies rather than answers. The results of the students' mathematical work, after implementing a sequence of tasks on fractions, are presented in this article.

For the study we set out to address the question: what is the argumentation work put into play in a virtual class context where a task is used in an online assessment artifact for a fractions task? And in order to answer it, an intervention consisting of two lessons and an assessment was carried out.

In the intervention, students were first asked to find a fraction of the form $a / b$ with $a$ and $b$ in the integers, between $1 / 4$ and $2 / 4$. Because of the density of rationals, this question has infinite solutions and once the answer was entered, the system evaluated whether or not it was in the interval and whether or not it complied with the requested format, and provided feedback. It also gave reasons why the answer was correct or partially correct. The situation evolved from the discussion work and ended with a question asking to find a sequence with infinite fractions, first between $1 / 4$ and $1 / 2$ and then between two fractions with random values given by the platform.

After the individual work on the platform, a discussion began with the students about the strategies used, and they only stated two strategies: with decimals, and amplifying the numerator and denominator of each fraction by the same number. The latter strategy led to the following conjecture: if $1 / 4$ and $2 / 4$ were amplified by $n$ then $n-1$ fractions would appear between them. One of the students demonstrated this at the end of the class.
In addition, another strategy appeared in the discussion, which was trial and error, which allowed us to enter into an epistemic discussion. This discussion was characterized by a transition from instrumental arguments - such as "raising the fraction to minus 1 turns the inequality around", erroneous arguments, and some circular arguments - to discursive genesis (Kuzniak et al., 2016a), based on properties of the theoretical referential, which demonstrates a specific characteristic in the TG3 theme, determined as an emerging sub-theme.

In a second class, the question was extended to the search for infinite sequences of fractions that were between $1 / 4$ and $1 / 2$. This task was more complex for the students, but there were at least two groups that found some correct sequences. The difference between showing that a sequence holds for several values and proving for all natural $\mathrm{n}$ was discussed, which Stylianides and Stylianides (2009, p. 315) call empirical arguments versus a demonstration and which, depending on the task and how it is implemented, allows students to build a justification process in which they search for arguments in a theoretical referential.

Finally, in the assessment, each student was asked to enter a value between random fractions, say $a / b$ and $c / d$, on the platform. Then, they were asked to find an infinite sequence that was between $a / b$ and $c / d$, and to prove that such a sequence was between both given fractions. The answer and correction of the last two tasks was done manually. The main argument to show that an infinite sequence was between two fractions was analogous to the one shown in class 1, in other words, the structure of the argumentation became a symbolic artifact for all groups.

It is noted that it is difficult to know which way these discussions will go and that they depend to a large extent on the mediating role of the professor. As Yackel (2002) points out, it is the professor's role to recognize the importance and validity of the arguments, to know the conceptual possibilities of the students and to know the underlying mathematical concepts in order to move towards meaningful mathematical argumentation. It is difficult to think of an a priori planning to know where the discussion will lead, so the possibility of replicating the intervention is not what is demonstrated, but the process of argumentation itself.

In the literature review, it was found that there is consensus in differentiating between explanation, argumentation, proof and demonstration (Balacheff, 1987; Duval, 1993; Hanna, 2001; Stylianides et al., 2016). The MWS allowed us to characterize the different arguments and to understand the process performed by teacher to guide students' arguments towards demonstration. Moreover, thanks to the theoretical framework used, throughout the intervention, an interesting interplay between instrumental and discursive geneses can be perceived. If in class 2 
arguments appeared in the discursive dimension, these same arguments became symbolic artifacts when they justified their answers in the evaluation. As most students used the same argumentative schema, it could be interpreted as "a culturally coded sequence of actions that are continuously instantiated in social practice" (Radford, 2014, p. 417). The arguments constructed by one student in class 2 were shared with classmates, who adapted the justification to each pair of numbers randomly assigned to them by the platform. While it could be observed that in different instances the instrumental-discursive plane is activated (Kuzniak \& Richard, 2014), the qualities of the arguments underwent transformations thanks to the use of different artifacts and elements of the theoretical referential.

The roles of technology in the argumentation process are diverse. One of them to give students back the responsibility to engage with a response, so that everyone has something to say. In previous classes, in some ways, students did not feel engaged in responding to the questions posed, the discussions were scarce and forced. According to Solar and Piquet (2016), one of the conditions for promoting argumentation is to provide opportunities for participation. In this sense, the platform makes it possible to provide these opportunities explicitly. Also, when the platform intervenes with correction and automatic feedback, the information it delivers to the subject generates meanings, which must be questioned in order to select those that are epistemologically valid or, if they are not, to be clear about their relative validity (Flores et al., 2022). A second role, is that technology can be a mediation of epistemic interaction to work with argumentation. In the already cited works of Stupel and Ben-Chaim (2017), and Zengin (2017) the technology used is a dynamic geometry system where the interaction helps to develop conjectures and proof schemes, instead in this work, the interaction is through a validation system that allows students to know if the found fraction is valid or not, but does not allow the construction of this. One can hypothesize about what would happen to the mathematical work if a milieu (e.g., an applet) were available that would allow the construction of fractions in the interval $[0,1]$. This would help develop more geometric strategies and probably, inhibit the decimal amplification and conversion strategies observed in this work. Finally, we can conjecture that this role also depends on the students' prior knowledge. The results of this work show that the question on the platform was simple for those who responded, so it is possible that validation and feedback may have influenced the students' work less. If this same situation is worked with students of other levels or with less skills in fractions, we could think that the interactive role could play a more relevant role.

The literature analyzed shows that it is necessary to work on the development of argumentation in future teachers, both because it is a higher-order skill, and because the work on novice teachers shows weaknesses in this respect. Moreover, thanks to the fact that they are being trained as mathematics teachers, it can be seen how the didactic contract (Brousseau, 1998) obliges them to seek arguments based on mathematical properties rather than just solving, so it is possible that this same situation could work for students at other educational levels.

One of the perspectives of this work is to modify some didactic variables of this research. In the first place, to analyze the discussions that emerge in different educational contexts and whether it is possible to automate other questions that may eventually appear. For example, for example, with high school students. Also, modifications can be made to the task, such as those mentioned in the previous paragraph and some others on strategies: for example, the teacher can propose correct or incorrect strategies (for example: if $\mathrm{a} / \mathrm{b}<\mathrm{c} / \mathrm{d}$ then $(\mathrm{a}+\mathrm{c}) /(\mathrm{b}+\mathrm{d})$ is between both values?) and ask for arguments that question their validity and generality. In relation to the role of technology, another perspective is to investigate that a system is able to validate, automatically, whether a sequence is bounded, in particular, by two fractions, in order to serve as a form of experimentation for students, to reduce the correction times of professors, and through feedback, to encourage the search for sequences with other characteristics than those observed in this research.

Finally, Stylianides et al. (2016), points out that research designed to foster argumentation is scarce compared to those that focus on diagnoses about the difficulties that appear when working with this topic, in this sense, this work contributes as a proposal to develop argumentation in technological contexts and with future mathematics teachers.

Author contributions: All authors have sufficiently contributed to the study, and agreed with the results and conclusions.

Funding: No funding source is reported for this study.

Declaration of interest: No conflict of interest is declared by authors.

\section{REFERENCES}

Artigue, M. (2002). Learning mathematics in a CAS environment: The genesis of a reflection about instrumentation and the dialectics between technical and conceptual work. International Journal of Computers for Mathematical Learning, 7(3), 245-274. https:// doi.org/10.1023/A:1022103903080

Bachelard. (1938). La formation de l'esprit scientifique. Paris Vrin.

Balacheff, N. (1987). Processus de preuve et situations de validation [Proof process and validation situations]. Educational Studies in Mathematics, 18(2), 147-176. https:/ / doi.org/10.1007/BF00314724 
Balacheff, N. (2000). Procesos de prueba en los alumnos de matemáticas [Testing processes in mathematics students]. Una empresa docente.

Belin, M., \& Akar, G. K. (2020). The effect of quantitative reasoning on prospective mathematics teachers' proof comprehension: The case of real numbers. Journal of Mathematical Behavior, 57(June 2018), 100757.

https:/ / doi.org/10.1016/j.jmathb.2020.100757

Boyatzis, R. (1998). Transforming qualitative information: Thematic analysis and code development. Sage Publications.

Brousseau, G. (1998). Théorie des situations didactiques [Theory of didactic situations] (La pensée).

Coutat, S., \& Richard, P. (2011). Les figures dynamiques dans un espace de travail mathématique pour l'apprentissage des propriétés géométriques [Dynamic figures in a mathematical workspace for learning geometric properties]. Annales de Didactique et de Sciences Cognitives, 16, 97-126.

Creswell, J. W., \& Poth, C. N. (2017). Qualitative inquiry and research design: Choosing among five approaches. In Sage Publications.

Duval, R. (1993). Argumenter, demontrer, expliquer: continuité ou rupture cognitive? [Argue, demonstrate, explain: continuity or cognitive rupture ?] Petit $x, 31,37-61$.

Fernández, C., Llinares, S., \& Valls, J. (2012). Learning to notice students' mathematical thinking through online discussions. ZDM - International Journal on Mathematics Education, 44(6), 747-759. https:/ / doi.org/10.1007/s11858-012-0425-y

Flores, J., Gaona, J., \& Richard, P. (2022). Mathematical work in the digital age: Variety of tools and the role of geneses. In A. Kuzniak, E. Montoya, \& P. Richard (Eds.), Mathematical work in educational context - the Mathematical Working Space Theory perspective. Springer International Publishing.

Gaona, J. (2020). Panorama sobre los sistemas de evaluación automática en línea en matemáticas [An overview of online self-assessment systems in mathematics]. Revista Paradigma, 16, 53-81. https:/ / doi.org/10.37618/PARADIGMA.10112251.0.p53-80.id853

Gaona, J., Hernández, R., Guevara, F., \& Bravo, V. (2021). Influence of a function's coefficients and feedback of the mathematical work when reading a graph in an online assessment system. https://arxiv.org/pdf/2107. 11448.pdf

Hanna, G. (2001). Proof, explanation and exploration: An overview. Educational Studies in Mathematics, 44, 523. https:/ / doi.org/10.1023/ A:1012737223465

Henríquez-Rivas, C., \& Montoya-Delgadillo, E. (2015). Espacios de trabajo geométrico sintético y analítico de profesores y su práctica en el aula [Synthetic and analytical geometric workspaces of teachers and their practice in the classroom]. Enseñanza de Las Ciencias. Revista de Investigación y Experiencias Didácticas, 33(2), 51. https:/ / doi.org/10.5565/rev/ ensciencias. 1408

Henríquez-Rivas, C., \& Montoya-Delgadillo, E. (2016). El trabajo matemático de profesores en el tránsito de la geometría sintética a la analítica en el liceo [The mathematical work of teachers in the transition from synthetic geometry to analytics in high school]. Bolema - Mathematics Education Bulletin, 30(54), 45-66. https://doi.org/10.1590/19804415v30n54a03

Kuzniak, A., \& Richard, P. (2014). Espacios de trabajo matemático. Puntos de vista $\mathrm{y}$ perspectivas [Mathematical workspaces. Points of view and perspectives]. Revista Latinoamericana de Investigación En Matemática Educativa, 17(4), 1-8. https:// doi.org/10.12802/relime.13.1741a

Kuzniak, A., Nechache, A., \& Drouhard, J. P. (2016a). Understanding the development of mathematical work in the context of the classroom. ZDM Mathematics Education, 48(6), 861-874. https: / / doi.org/10.1007/s11858-016-0773-0

Kuzniak, A., Tanguay, D., \& Elia, I. (2016b). Mathematical working spaces in schooling: An introduction. ZDM - Mathematics Education, 48(6), 721-737. https://doi.org/10.1007/s11858-016$0812-\mathrm{x}$

Lo, J. J., Grant, T. J., \& Flowers, J. (2008). Challenges in deepening prospective teachers' understanding of multiplication through justification. Journal of Mathematics Teacher Education, 11(1), 5-22. https: / / doi.org/10.1007/s10857-007-9056-6

Mena-Lorca, A., Mena-Lorca, J., Montoya-Delgadillo, E., Morales, A., \& Parraguez, M. (2014). El obstáculo epistemológico del infinito actual: Persistencias y categorías de análisis [The epistemological obstacle of the current infinity: Persistence and categories of analysis]. Revista Latinoamericana de Investigación En Matemática Educativa, 17(1), 9-32. https:/ / doi.org/10.12802/relime.13.1832

MINEDUC, C. de E. (2020). Impacto del Covid-19 en los resultados de aprendizaje y escolaridad en Chile [Impact of Covid-19 on Learning and Schooling Outcomes in Chile]. https://chile.un.org/es/102663impacto-del-covid-19-en-los-resultados-deaprendizaje-y-escolaridad-en-chile

MINEDUC. (2019). Bases Curriculares $3^{\circ}$ y $4^{o}$ medio [Curricular bases 3rd and 4th grade].

Montoya-Delgadillo, E., Mena-Lorca, A., \& Mena-Lorca, J. (2014). Circulaciones y génesis en el espacio de trabajo matemático [Circulations and genesis in the mathematical workspace]. Revista Latinoamericana 
de Investigación En Matemática Educativa, 17(4-1), 191-210. https:/ / doi.org/10.12802/relime.13.1749

Montoya-Delgadillo, E., Mena-Lorca, J., \& Mena-Lorca, A. (2016). Estabilidad epistemológica del profesor debutante y espacio de trabajo matemático [Epistemological stability of the beginning professor and mathematical workspace]. Bolema Mathematics Education Bulletin, 30(54), 188-203. https:/ / doi.org/10.1590/1980-4415v30n54a09

Nagel, K., Schyma, S., Cardona, A., \& Reiss, K. (2018). Análisis de la argumentación matemática de estudiantes de primer año [Analysis of the mathematical argumentation of first-year students]. Pensamiento Educativo, 55(1), 1-13. https:/ / doi.org/10.7764/PEL.55.1.2018.10

Peirce, C. S. (1932). Collected papers of Charles Sanders Peirce. II: Elements of logic. Harvard University Press.

Peña, C. N., Pino-Fan, L. R., \& Assis, A. (2021). Normas que regulan la gestión de clases virtuales de matemáticas en el contexto COVID-19 [Norms that regulate the management of virtual mathematics classes in the context of COVID-19]. Uniciencia, 35(2), 1-20. https:// doi.org/10.15359/ru.35-2.21

Pizarro, N., Albarracín, L., \& Gorgorió, N. (2018). Actividades de estimación de medida: La interpretación de los docentes de Educación Primaria [Measurement estimation activities: The interpretation of primary education teachers]. Bolema: Boletim de Educação Matemática, 32(62), 11771197. https:/ / doi.org/10.1590/1980-

$4415 \mathrm{v} 32 \mathrm{n} 62 \mathrm{a} 21$

Radford, L. (2014). On the role of representations and artefacts in knowing and learning. Educational Studies in Mathematics, 85(3), 405-422. https:/ / doi.org/10.1007/s10649-013-9527-x

Rodríguez-Jara, M. A., Mena-Lorca, A., Mena-Lorca, J., Vásquez, P., \& del Valle, M. (2019). Construcción cognitiva del conjunto solución de un sistema de ecuaciones lineales con dos incógnitas [Cognitive construction of the solution set of a system of linear equations with two unknowns]. Enseñanza de Las Ciencias, 1, 71-92. https://doi.org/10.5565/rev/ ensciencias. 2194

Solar, H. (2018). Implicaciones de la argumentación en el aula de matemáticas [Implications of argumentation in the mathematics classroom]. Revista Colombiana de Educación, 1(74), 155-176. https:// doi.org/10.17227/rce.num74-6902

Solar, H., \& Deulofeu, J. (2016). Conditions to promote the development of argumentation competence in the mathematics classroom. Bolema: Boletim de Educação Matemática, 30(56), 1092-1112. https:/ / doi.org/10.1590/1980-4415v30n56a13

Stupel, M., \& Ben-Chaim, D. (2017). Using multiple solutions to mathematical problems to develop pedagogical and mathematical thinking: A case study in a teacher education program. Investigations in Mathematics Learning, 9(2), 86-108. https:// doi.org/10.1080/19477503.2017.1283179

Stylianides, A., \& Stylianides, G. (2009). Proof constructions and evaluations. Educational Studies in Mathematics, 72(2), 237-253. https:/ / doi.org/10.1007/s10649-009-9191-3

Stylianides, A., Bieda, K., \& Morselli, F. (2016). Proof and argumentation in mathematics education research. In Á. Gutierres, G. Leder, \& P. Boero (Eds.), The second handbook of research on the psychology of mathematics education (Issue Icmi, pp. 315-351). https://doi.org/10.1007/978-94-6300-561-6_9

Stylianides, G., \& Stylianides, A. (2009). Facilitating the transition from empirical arguments to proof. Journal for Research in Mathematics Education, 40(3), 314-352.

https://doi.org/10.5951/jresematheduc.40.3.0314

Stylianides, G., Stylianides, A., \& Shilling-Traina, L. (2013). Prospective teachers' challenges in teaching reasoning-and-proving. International Journal of Science and Mathematics Education, 11(6), 1463-1490. https:/ / doi.org/10.1007/s10763-013-9409-9

Yackel, E. (2002). What we can learn from analyzing the teacher's role in collective argumentation. Journal of Mathematical Behavior, 21(4), 423-440. https:/ / doi.org/10.1016/S0732-3123(02)00143-8

Zengin, Y. (2017). The effects of GeoGebra software on pre-service mathematics teachers' attitudes and views toward proof and proving. International Journal of Mathematical Education in Science and Technology, 48(7), 1002-1022. https://doi.org/ 10.1080/0020739X.2017.1298855

\section{http://www.ejmste.com}

